\title{
Distribution of Bovine Demodicosis in the Forest-Steppe Zone of the Northern Trans-Urals
}

\author{
Olga A. Stolbova \\ Institute of Biotechnology and Veterinary Medicine, Federal State Budgetary Educational Institution of Higher \\ Education "State Agrarian University of the Northern Trans-Urals" (625003, Russia, Tyumen, Respubliki Str. 7) \\ notghsa@mail.ru \\ “All-Russian Research Institute of Veterinary Entomology and Arachnology" - Branch of the Federal State \\ Budgetary Institution of Science, Federal Research Center of the Tyumen Scientific Center, the Siberian Branch \\ of the Russian Academy of Sciences, Russia, 625041, Tyumen, Institutskaya Str. 2; \\ vniivea@mail.ru
}

Received: 21st August 2020, Accepted: 14th September 2020, Published: 31st October 2020

\begin{abstract}
Researchers and veterinarians engaged in animal husbandry constantly note the relevance of the topic of combating ecto- and endoparasites of cattle, since their associative parasitism causes huge economic damage, which consists of a decrease in meat and milk productivity, breeding value, as well as a lack of high-quality tanning raw materials. Today, a special place among the diseases of the parasitic system in cattle belongs to demodicosis, which has a significant distribution in various climatic zones of the Russian Federation and other countries. In this regard, the research objective was to study the prevalence of demodectic invasion in cattle in the forest-steppe zone of the Northern Trans-Urals. To study the spread of demodicosis in cattle, a clinical examination of 21,554 heads was carried out in 2002-2018 with confirmation of the diagnosis by microscopy of skin scrapings of clinically sick animals and the detection of demodectic mites at various stages of development. Based on the results of the data obtained, we can state the extensive distribution of demodicosis in cattle in the forest-steppe zone of the Northern Trans-Urals. Thus, the average long-term extensiveness of the invasion of cattle by demodectic mange in the northern forest-steppe was $15.67 \pm 1.21 \%$, and in the subzone of the southern forest-steppe was $10.88 \pm 0.74 \%$.
\end{abstract}

Keywords

Cattle, Ticks, Acarosis, Demodicosis, Demodex Bovis, Northern Trans-Urals

\section{Introduction}

The state agrarian policy is an integral part of the state socio-economic policy aimed at the sustainable development of agriculture and rural areas. Sustainable development of rural areas is understood as their stable socio-economic development, an increase in agricultural production, an increase in the efficiency of agriculture, the achievement of full employment of the rural population and an increase in its standard of living and rational use of land $[1,3,4]$.

The agro-industrial complex of the Tyumen region is the most important sector of the national economy and the main source of food resources that ensure national security. The production of livestock products largely determines the economic and financial condition of the entire agro-industrial complex. At each stage of development of animal husbandry, the tasks of improving the industry are becoming more complex and broader. Their successful solution requires animals with high productivity, reproductive capacity, and strong immunity; no less important are their maintenance condition, which should be based on the biological laws of the development of the organism and fully satisfy the physiological needs of animals $[3,4,6,9]$.

The main reason for the emergence and development of skin pathologies of parasitic etiology in cattle today are violations of zoohygienic requirements for feeding and keeping of and caring for animals, as well as noncompliance with microclimate parameters, in turn, reduces the body's resistance and predisposes to the occurrence of diseases of various etiologies, and in particular invasive. Currently, one of the problems of invasive pathology in cattle is demodicosis $[1,2,5,10-15]$.

Bovine demodicosis is an enzootic disease caused by the microscopic Demodex bovis mange, parasitizing single colonies in the hair follicles of the sebaceous and sweat glands. The disease manifests itself as focal inflammation of the skin in the form of tubercles ranging in size from 0.2 to $1 \mathrm{~cm}$ in diameter. In the center of the colonies, a skin scab forms; skin in these areas thickens and loses its elasticity. In these areas of the skin, vortex hair formations or their absence are found. At the beginning, the disease is clinically unnoticeable. In advanced cases, sick animals show lethargy, depression, decreased appetite, a sharp decrease in milk and meat productivity $[9,12$, $14,18]$.

The objective of research is to study the distribution of bovine demodicosis in various municipal areas of the forest-steppe zone of the Northern Trans-Urals. 


\section{Materials and Methods}

The research was carried out in 2002 to 2018 on the basis of the departments of non-infectious diseases of farm animals and infectious and invasive diseases of the Institute of Biotechnology and Veterinary Medicine of the Federal State Budgetary Educational Institution "State Agrarian University of the Northern Trans-Urals" (FSBEI HE SAU, Northern Trans-Urals), laboratories of acarology of the All-Russian Scientific Research Institute of Veterinary Entomology and Arachnology - a branch of the Tyumen Scientific Center, SB RAS and in farms of various forms of ownership of the Tyumen region.

The study of the clinical signs of demodicosis was carried out by examination and palpation of the skin and hair. During examination, we looked for the presence of alopecia, ruffled hair, shine of the hairline, on palpation - skin elasticity, peeling, thickening, tubercles, crusts, hyperemia. To identify sick animals used methods of examination and palpation of the skin and hair and microscopic examination of the contents of demodectic colonies. During examination, attention was paid to baldness and "vortex" of hair, compacted tubercles, thickening of the skin, crust, etc. on palpation. The diagnosis was confirmed by microscopic examination of samples taken from the affected areas. The contents of demodectic tubercles were obtained using a deep scraping with a scalpel, then the contents were transferred to a glass slide, poured with a few drops of water or paraffin oil, lightly distributed with a scalpel or needle were distributed over the glass and examined under a small magnification of the microscope in a darkened field of view. In the absence of clinical signs of demodicosis, the method of plucking the hairline proposed by B.A. Frolov and S.V. Larionov (1981) was used on an area of 1.5-2 $\mathrm{cm}^{2}$ was used in the places of the most frequent localization of demodectic colonies (neck, shoulder, shoulder blades) and taking scrapes of skin and roots of pulled hair from these places in order to detect demodectic mange. In other cases, after removing the scab, a small amount of the pasty content consisting mainly of mature D. bovis mange could be squeezed out of the nodule [5]. The diagnosis was confirmed by microscopic examination of samples taken from the affected areas. To obtain the contents of the demodectic tubercles, the hair was cut off, the center of the tubercle was disinfected and punctured with an injection needle to a depth of 2-3 $\mathrm{mm}$, after which the contents were squeezed out and transferred to a glass slide. A few drops of warm distilled water were added to the slide, lightly distributed with a scalpel or needle and examined under a small magnification of the microscope in a darkened field of view. The processing of the data on the degree of invasion was carried out using the indicator of the invasion extensiveness (EI). The results obtained were processed statistically, taking into account the mean values, their errors and the level of reliability $(\mathrm{P})$ using the Student's t-test in Microsoft Excel and Biostat.

\section{Results and Discussion}

This research activity was concentrated in the forest-steppe zone of the Tyumen region, while the research part was carried out in the Ishimsky, Tyumensky, Zavodoukovsky, Golyshmanovsky, Isetsky, Omutinsky and Yalutorovsky districts. Analysis of the distribution of bovine demodicosis in the conditions of the Northern TransUrals showed that demodectic invasion is widespread among cattle. In the subzone of the northern forest-steppe, 17,328 heads of cattle were examined, of which 2715 (EI-15.67 $\pm 1.21 \%$ ) heads of cattle were identified with clinical signs of demodicosis (Table 1).

The data presented in the table indicate a widespread demodectic invasion among cattle. Analyzing the results of clinical signs in the Ishimsky district, where 3176 heads of cattle were examined, and 490 animals were diagnosed with demodicosis $(15.43 \pm 2.38 \%)$.

In the Tyumensky district, 601 of 3380 animals examined were diagnosed with demodicosis $(17.78 \pm 1.058 \%)$. During microscopy skin scrapings with the contents of demodectic colonies showed Demodex bovis mange at all stages of development (egg-nymph-protonymph-deutonymph-imago). The extensiveness of the invasion ranged from $14.25-25.85 \%$. The extensiveness of the invasion with demodectic mange in different years of the study ranged from 6.71 to $28.85 \%$.

The incidence of animals in the Uporovskiy district during the study period was $20.85 \pm 1.93 \%$, while over the entire period, 1755 animals were examined and clinical signs of demodicosis were detected in 366 heads. During the observation period, the extensiveness of the invasion of livestock ranged from 11.29 to $42.44 \%$. 
Table 1: Distribution of Bovine Demodicosis in the Forest-Steppe Zone of the Northern Trans-Urals

\begin{tabular}{|l|c|c|c|}
\hline \multirow{2}{*}{ Study region } & \multirow{2}{*}{$\begin{array}{c}\text { Number of cattle } \\
\text { examined }\end{array}$} & \multicolumn{2}{c|}{ humber of sick animals } \\
\cline { 3 - 4 } & \multicolumn{2}{c|}{ Northern forest-steppe subzone } & IE, \% \\
\hline Ishimsky & 3176 & 490 & $15.43 \pm 2.38$ \\
\hline Tyumensky & 3380 & 601 & $17.78 \pm 1.06$ \\
\hline Uporovsky & 1755 & 366 & $20.85 \pm 1.93$ \\
\hline Golyshmanovsky & 1377 & 221 & $11.5 \pm 2.83$ \\
\hline Isetsky & 1942 & 232 & $11.95 \pm 1.88$ \\
\hline Omutinsky & 2429 & 261 & $16.64 \pm 2.22$ \\
\hline Yalutorovsky & 3269 & 544 & $\mathbf{1 5 . 6 7 \pm 1 . 2 1}$ \\
\hline Total for subzone & $\mathbf{1 7 , 3 2 8}$ & $\mathbf{2 7 1 5}$ & $15.68 \pm 1.76$ \\
\hline & Southern forest-steppe subzone & $11.89 \pm 1.67$ \\
\hline Armizonsky & 791 & 124 & $10.49 \pm 1.33$ \\
\hline Kazansky & 1017 & 121 & $7.45 \pm 1.58$ \\
\hline Sladkovsky & 1143 & 120 & $\mathbf{1 0 . 8 8} \pm \mathbf{0 . 7 4}$ \\
\hline Abatsky & 1275 & 95 & $\mathbf{4 6 0}$ \\
\hline Total for subzone & $\mathbf{4 2 2 6}$ & &
\end{tabular}

In the Golyshmanovsky district, we examined 1377 heads of cattle and found demodectic invasion in 221 animals, which amounted to $21.5 \pm 2.83 \%$. The minimum indicator of the invasion of animals was $9.83 \%$ in 2005 , and the maximum - $21.68 \%$ in 2017.

The examination of 1942 animals in the Isetsky region for the entire observation period established demodectic invasion in 232 heads, which amounted to $11.95 \pm 1.875 \%$. Invasion by Demodex bovis varied widely in different years from $4.76 \%$ to $23.81 \%$.

The examination of 2429 animals in the Omutinsky district found clinical signs and the presence of $D$. bovis in 261 heads, which amounted to $10.75 \pm 1.52 \%$. The extent of the invasion by demodicosis in different years of the study ranged from $5.08-17.74 \%$.

The distribution of demodicosis in cattle in the Yalutorovsky district was studied in farms of various forms of ownership, where 3269 heads from agricultural enterprises and the private sector were examined, demodicosis was detected in 544 animals $(16.64 \pm 2.22 \%)$. During the observation period, the extensibility varied from 9.56 to $30.93 \%$.

During clinical studies in the southern forest-steppe subzone, we examined 4226 heads of cattle, among which the diagnosis of demodicosis was confirmed in 460 heads (EI - 10.88 $\pm 0.74 \%$ ) (Table 1).

To the greatest extent, demodecosis was diagnosed in the Armizonsky district in 124 of 791 examined animals (EI-15.68 $\pm 1.76 \%)$

The long-term average extensiveness of demodectic invasion in animals in the Kazansky, Sladkovsky, and Abatsky districts was in the range of $11.89 \pm 1.67 \%, 10.49 \pm 1.33 \%$ and $7.45 \pm 1.58 \%$, respectively.

\section{Conclusion}

Thus, based on the results of the data obtained, we can state the extensive distribution of demodicosis in cattle in the forest-steppe zone of the Northern Trans-Urals. Thus, the average long-term extensiveness of the invasion of cattle by demodectic mange in the northern forest-steppe was $15.67 \pm 1.21 \%$, and in the subzone of the southern forest-steppe was $10.88 \pm 0.74 \%$.

\section{Acknowledgements}

The article was prepared as the part of the topics of the Federal Research Institute "The Study of New Antiparasitic Drug Effectiveness" and the Basic Research Program of the Russian Academy of Sciences.

\section{References}

1. Burmistrova M.I. Types of skin lesions in cattle with demodicosis // Collection: Questions of veterinary medicine and veterinary biology. Collection of scientific works of young scientists. Ministry of Agriculture of the Russian Federation, K.I. Skriabin Moscow State Academy of Veterinary Medicine and Biotechnology. Moscow, 2015. P. 29-32.

2. Burmistrova M.I., Vasilevich F.I., Gordienko I.M. Evaluation of the quality of leather raw materials in case of demodicosis // Veterinarian. - 2014. - No. 5. - P. 57-59.

3. Glazunova L.A., Glazunov Yu.V., Ergashev A.A. Ecological-Epizootical Situation on Telasiosis Among Large Cattle In Northern Ural Region // Research Journal of Pharmaceutical Biological and Chemical Sciences. - 2018. - Vol.9. - № 4. - P. 1687-1693. 
4. Glazunov Iu.V., Stolbova O.A. The efficacy of insecticide and acaricidal drugs in the disacarization of objects of veterinary supervision // Bulletin of Veterinary Medicine. - 2014. - No. 2 (69). - P. 26-29.

5. Larionov S.V., Vasilevich F.I. Demodecosis of animals. Monograph. - M.: IMA-PRESS, 2001. - 251 p.

6. Sivkov G.S., Domatskii V.N., Metelitsa A.K., Glazunov Iu.V., Korotaeva O.A., Maslova E.N., Vasilevich F.I., Vodianov A.A., Larionov S.V. Therapy and prevention of animal acaroses in the Russian Federation // Guidelines. - Tyumen, 2010. - 56 p.

7. Sivkov G.S. et al. Protection of cattle from pathogens: guidelines. - Tyumen, 2010. - $152 \mathrm{p}$.

8. Skosyrskikh L.N. Characterization of demodectic skin lesions during leather processing // Bulletin of the Krasnoyarsk State Agrarian University: scientific and technical journal. - Krasnoyarsk. - 2004. - No. 6. - P. 147-149.

9. Skosyrskikh L.N., Stolbova O.A. Distribution and seasonal dynamics of cattle demodecosis in the Tyumen region // Bulletin of the Novosibirsk State Agrarian University. - 2011. - No. 4 (20). - P. 94-96.

10. Skosyrskikh L.N. Assessment of demodectic lesions in the leather semi-finished product and finished goods // Science and Technology of Kazakhstan. Scientific journal of S. Toraigyrov Pavlodar State University. No. 2. - 2004. - P. 103-105.

11. Stolbova O.A., Glazunova L.A., Nikonov A.A., Glazunov Iu.V., Skosyrskikh L.N. Insects and ticks - cattle parasites in the Northern Trans-Urals // Basic research. - 2014. - No. 11-12. - P. 2650-2655.

12. Stolbova O.A., Skosyrskikh L.N. The study of stress resistance in cattle with demodicosis in the Tyumen region // Issues of regulatory regulation in veterinary medicine. - 2015. - No. 2. - P. 84-86.

13. Stolbova O.A. Demodecosis of cattle in the Northern Trans-Urals // Theory and practice of controlling parasitic diseases. - 2018. - No. 19. - P. 463-466.

14. Stolbova O.A., Glazunov Iu.V., Nikonov A.A. Skin pathologies in cattle in the Northern Trans-Urals // International Research Journal. - 2016. - No. 8-2 (50). - P. 28-30.

15. Stolbova O.A., Skosyrskih L.N. Acaricidal activity of Abifipr in cattle demodecosis // Bulletin of Krasnoyarsk State Agrarian University. 2016. No. 1 (112). P. 145-149.

16. Stolbova O.A., Skosyrskikh L.N. Calculation of the cost of using acaricides for cattle demodecosis // Bulletin of Stavropol AIC. - 2016. - No. 2 (22). - P. 54-57.

17. Stolbova O.A., Glazunov Yu.V., Skosyrskikh L.N. Ticks-parasites of dogs in Northern Trans-Urals // Indo American Journal of Pharmaceutical Sciences. - 2018. - V. 5. - No. 3. - P. 1675-1682.

18. Stolbova O.A. Parasitic activity of demodex ticks among cattle // Indo American Journal of Pharmaceutical Sciences. - 2019. - Vol.6 - P. 13337-13341. 